$\begin{array}{llllllll}A & b & s & t & r & a & c & t\end{array}$ The rapid growth of the Internet and electronic commerce stimulates new digital innovations. Electronic markets can influence both the adoption and diffusion processes of digital innovations in significant ways. The difficulties for market transactions of information goods and the change from free to paid content on websites in recent years has led to research questions about how individuals decide whether and when to adopt paid content innovations and how this innovation diffuses throughout a population. This paper presents empirical evidence regarding the adoption and diffusion process of paid content. It focuses on the differences of the adoption and diffusion process of different paid content types dependent on: (1) the existence of established, non-digital counterparts; (2) experience and familiarity with paid content and micropayment services; and (3) economic advantage and perceived convenience. Results pave a ground for a better understanding how paid content will support knowledge work in the future.

Keywords: adoption, diffusion, electronic markets, information goods, paid content

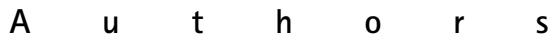

Florian Stahl

(florian.stahl@unisg.ch) is a postdoctoral research fellow at Columbia Business School in New York as well as at the Center of Business Metrics, University of St. Gallen, Switzerland. He received a Master in Economics (lic.oec.) from the University of Zurich, Switzerland in 2001 and a doctoral degree (PhD equivalent) in Business Administration from University of St. Gallen, Switzerland in 2005.

Wolfgang Maass

(wolfgang.maass@hs-furtwangen.de) is a Professor of Digital Media at

Furtwangen University (HFU), Germany. He received his diploma and doctoral degree (1996) in Computer Science from the Saarland University, Germany. From 1998 to 2005 he led the research group on Intelligent Media at the University of St. Gallen, Switzerland.

\title{
Adoption and Diffusion in Electronic Markets: An Empirical Analysis of Attributes Influencing the Adoption of Paid Content
}

FLORIAN STAHL AND WOLFGANG MAASS

\section{INTRODUCTION}

In the field of marketing, research on new product diffusion has traditionally focused on the adoption of innovations (e.g., Mahajan and Muller 1979; Mahajan et al. 1990; Rogers 2003; Shih and Venkatesh 2004). The adoption-diffusion research examines the process by which an innovation reaches a critical mass of adopters, the diffusion is accelerated, and innovation is considered successful (Mahajan et al. 1990).

In recent years, research on the adoption and diffusion processes of digital products has increasingly focused on the Internet in particular because of the specific characteristics of electronic markets and digital products. The Internet stimulates the innovation of new digital products and new types of business models - paid content on websites is one example of this potential for innovation. Paid content is a special form of information good (Brandtweiner 2000; Clarke 2005; Shapiro and Varian 1999; Varian 1998) and counts as a digital product (Brandtweiner 2000; Choi et al. 1997; Clarke 2005). In this paper the term paid content is used for non-free sales and distribution of information-based content products.

Paid content is of particular interest for the discussion of adoption and diffusion processes on the Internet as after the consolidation of the Internet boom in 2001 and the decline of advertising revenues many firms changed their business models and moved to selling information goods which had been freely available up until then. This also required a change of consumer behaviour, because consumers are required to pay for formerly free digital content.

The rapid growth of the Internet, new digital innovations and the change from free to paid content led to new research questions about how individuals decide whether and when to adopt an innovation (Eastin 2002) and how the innovation diffuses throughout a population (Rangaswamy and Gupta 2000). Adoption means the decision of an individual to make use of an innovation as the best course of action available relative to invested resources. Rogers (Rogers 2003: 19) defines the innovation decision process as a five-step process on the individual level: (1) gain of initial knowledge of an innovation; (2) formation of an attitude towards 
the innovation; (3) decision whether to adopt or reject; (4) implementation and usage of the new idea; and (5) confirmation of this decision. The rate of adoption is defined as the relative speed with which members of a social system adopt an innovation. Rogers defines diffusion as the process by which an innovation is communicated through certain channels over time among the members of a social system (Rogers 2003: 5).

The adoption and diffusion of digital products in electronic markets have been analysed in various papers (Bughin 2003; Kshetri and Dholakia 2002; Rangaswamy and Gupta 2000). These analyses focus on free digital products such as free software or e-commerce of nondigital products, where the adoption decisions occur online and physical exchange takes place outside digital media.

As mentioned, paid content is also a kind of a digital product, but with the special characteristics of information goods. According to Hal Varian information goods are experience goods with economies of scale that would seem to cause difficulties for market transactions: 'you must experience an information good before you know what it is' (Varian 1998). This leads to the research question as to which attributes influence the e-commerce adoption of paid content and whether the existence of non-digital counterparts influences adoption and diffusion of paid content.

In this paper an empirical analysis of the adoption and diffusion process of paid content in the tradition of formal marketing-oriented models is presented. In this context the analysis focuses on the impact of an established non-digital counterpart on the adoption and diffusion process of digital paid content.

The following section will give an overview over the adoption and diffusion literature. Based on these theories an approach will be derived and empirically tested. In the last section the impact of the empirical findings on the adoption and diffusion theories and the implications of these empirical findings are discussed.

\section{ADOPTION AND DIFFUSION IN ELECTRONIC MARKETS: A LITERATURE OVERVIEW}

In this section, for analysing and exploration of the attributes that influence the e-commerce adoption of paid content the concept of adoption and diffusion will be presented along with representative references. The concept of diffusion is a means of analysing passive spreads of innovations across populations (Rogers 2003). Depending on the research tradition, theories adopt an individualistic, i.e., subjective (TRA (Fishbein and Ajzen 1975), TAM (Davis 1989), Motivational Model (Davis et al. 1992), MPCU (Thompson et al. 1991), IDT (Rogers 2003), SCT (Compeau and Higgins 1995)) or a group-oriented, objective stance (Bass 1969; Eastin 2002; Rangaswamy and Gupta
2000). Individualistic models stem from socio-psychological theories such as Bandura's social cognitive theory (Bandura 1977, 1986) and investigate factors that influence an individual's decision making regarding the adoption of innovations. Rogers' seminal work (Rogers 2003) highlights the importance of attributes such as relative advantage (Moore and Benbasat 1991), compatibility to an individual's existing knowledge (Taylor and Todd 1995), social factors (e.g., Fishbein and Ajzen 1975; Thompson et al. 1991) and innovation-dependent attributes, such as complexity (Thompson et al. 1991), trialability and observability (Rogers 2003). Studies concentrating on the adoption of information technology clarified these attributes by focusing on a cluster of attributes that influence user acceptance such as individual attitudes (Fishbein and Ajzen 1975), motivation (Davis et al. 1992), affects (Compeau and Higgins 1995), subjectively perceived usefulness (Davis 1989), perceived ease-of-use of IT-related innovations (Davis 1989; Moore and Benbasat 1991), self-efficacy (Compeau and Higgins 1995) and outcome expectations (Compeau and Higgins 1995).

Objective models are influenced by economic growth models (e.g., the early Bass model on results such as Haines (1964)) and in particular by models for the development of optimal pricing strategies (Krisnan et al. 1999; Robinson and Lakhani 1975). In these models, innovations are given by products or services on which consumers make rational cost-benefit decisions (e.g., Rogers 2003).

In this paper we will adopt a group-oriented, objective stance which allows the analysis of adoption and diffusion effects of paid content on electronic markets. There is a vast amount of literature on adoption and diffusion processes regarding innovations and electronic markets. Explaining user acceptance of new technologies and innovations is often described as one of the most mature research areas in contemporary information system (IS) literature (e.g., Hu et al. 1999; Venkatesh et al. 2003). Within the literature on adoption and diffusion processes distinct streams can be identified according to which the literature can be categorized. According to the classification of Venkatesh et al. (2003) one stream of research focuses on individual acceptance of technology by using intention or usage as a dependent variable (e.g., Compeau and Higgins 1995; Davis et al. 1989). 'Other streams have focused on implementation success at the organizational level (Leonard-Barton and Deschamps 1988) and tasktechnology fit (Goodhue 1995; Goodhue and Thompson 1995), among others' (Venkatesh et al. 2003). Even though each of these streams makes important and unique contributions to the literature on adoption and diffusion, only models that focus on individual acceptance of innovations will be included in the present review. In this context Venkatesh et al. (2003) have identified several key competing models for 
individual acceptance of innovations: the Theory of Reasoned Action (TRA), the Technology Acceptance Model (TAM), the Motivational Model, the Theory of Planned Behaviour, the Social Cognitive Theory and the Innovation Diffusion Theory.

The Theory of Reasoned Action (TRA) (Fishbein and Ajzen 1975) is an intention model from social psychology for predicting and explaining virtually any human behaviour in different contexts and across a wide variety of domains (Ajzen and Fishbein 1980: 4). 'According to TRA, a person's performance of a specified behaviour is determined by his or her behavioural intention (BI) to perform the behaviour, and $\mathrm{BI}$ is jointly determined by the person's attitude (A) and subjective norm (SN) concerning the behaviour in question' (Davis et al. 1989: 983). Davis et al. adapt the TRA and use this theory as a basis for their Technology Acceptance Model (TAM) which is specially tailored to modelling user acceptance of information systems. TAM is considerably less general than TRA, designed to apply only to computer usage behaviour (Davis et al. 1989: 985).

The Motivational Model (MM), also a theory from social psychology, supports general motivation as an explanation for behaviour. The MM distinguishes between extrinsic motivation und intrinsic motivation. Extrinsic motivation means that users will want to perform an activity 'because it is perceived to be instrumental in achieving valued outcomes that are distinct from the activity itself, such as improved job performance, pay, or promotions' (Davis et al. 1992: 1112; Venkatesh et al. 2003: 428). Intrinsic motivation, however, means that users will want to perform an activity 'for no apparent reinforcement other than the process of performing the activity per se' (Davis et al. 1992: 1112; Venkatesh et al. 2003: 428). Several studies have adapted motivational theory for specific contexts. Within the information system domain, Davis et al. (1992) have applied motivational theory to understand new technology adoption and use.

The Theory of Planned Behaviour (TPB) is, analogous to the Technology Acceptance Model (TAM), an extension of the Theory of Reasoned Action (TRA). The TPB is a theory in psychology about the link between attitudes and behaviour and was proposed by Icek Ajzen (1991). Harrison et al. (1997), Mathieson (1991) and Taylor and Todd (1995) show a successful application of the TPB to the understanding of individual acceptance and usage of many different technologies (Venkatesh et al. 2003: 429).

The Social Cognitive Theory (SCT), developed by Albert Bandura (Bandura 1986) since 1960, stemmed from the Social Learning Theory and has its origins in the discipline of psychology. The SCT describes how people understand themselves and others in society and social situations. Compeau and Higgins (1995) extended the SCT to study computer use and the use of information technology in general and developed the computer self-efficacy (CSE) constructs. Computer self-efficacy is defined as the judgment of one's capability to use an information technology (Compeau and Higgins 1995).

The last stream of literature about adoption and diffusion of information and Internet technologies is the so-called Innovation Diffusion Theory (IDT) developed by Everett Rogers in 1962 (Rogers 2003). Rogers categorizes customers into segments such as innovators $(2.5 \%)$, early adopters (13.5\%), early majority (34\%), late majority (34\%) and laggards (16\%), based on a bell curve. Each adopter's willingness and ability to adopt an innovation depends on their awareness, interest, evaluation, trial and adoption. In his model the diffusion process predicates the time path of adoption of new products and technologies in a market in an S-curve, as the early adopters select the technology first, followed by the majority, until a technology or innovation is common.

Various models have been developed for diffusion processes. The original diffusion model provided a probabilistic approach based on the hazard function, which determines the likelihood that an agent who has remained a non-adopter of knowledge - typically an innovative product - through time $t$ will become an adopter in the next temporal unit (Mahajan et al. 1990). This early model focused on effects that are supposed to be correlated with innovators, that is, those agents who adopt and apply knowledge solely on information they receive from agents outside the social network, for example, from news and other media.

Based on the understanding and the conceptual and empirical similarities of the different prominent models about the individual acceptance of new information technologies above, Venkatesh et al. (2003) developed a unified model, called the United Theory of Acceptance and Use of Technology (UTAUT). The UTAUT model assumes that four core determinants influence behavioural intentions - performance expectancy, effort expectancy, social influence and facilitating conditions that in turn influence actual consumer's use behaviour of information technology. Empirically UTAUT explains as much as $70 \%$ of the variance in intention of individual acceptance and usage decisions in organizations.

\section{Research on adoption and diffusion in the context of electronic markets}

When the Internet and subsequently e-commerce started to spread in the mid 1990s, researchers began to direct their attention to adoption and diffusion processes on electronic markets. Adoption and diffusion on electronic markets were often analysed with regard to network effects and externalities) Choi et al. 1997; Malone et al. 1987). In a non-technical overview Shapiro and Varian illustrate the importance and the interrelation of network externality and adoption issues 
(Shapiro and Varian 1999). Based on the literature on adoption and diffusion, Rangaswamy and Gupta (2000) propose an explanation for the development of the Internet. Using empirical analysis they explore early adopters' attitudes towards the Internet and perceptions of online versus offline vendors. They found that among very early adopters shopping was the primary reason for using the Web.

Transactions Costs Theory (TCT) has also been used extensively for the analysis of adoption and diffusion processes on the Internet. Liang and Huang (1998) model adoption in the electronic marketplace by using the Transactions Cost Theory. They show the strong interrelation of transaction costs and uncertainty and asset specificity. Ward and Davies (1999) use the TCT to analyse consumers' substitution between online, traditional retail and direct mail.

Adoption and diffusion processes on the Internet are most commonly explained in scientific publications using Roger's IDT. According to the IDT, the adoption of technological innovations is a function of one's innovativeness or willingness to try new products (Rogers 2003). Different publications and studies on the adoption process of new technologies find that the rate of adoption - the relative speed with which an innovation is adopted by members of a social system (Rogers 2003: 221) - depends on demographic variables and perceived characteristics of innovations (Rogers 2003: 222). For example, Dutton et al. (1987) show that early adopters of computers and cable television tend to be better educated and have a higher socioeconomic status (SES). An early framework for examining the commercial development of the Web was developed by Hoffman et al. (1995). In their framework they explore the impact of the Internet as a distribution channel and as a medium for marketing communication. Eastin's 2002 study analyses different concepts of adoption by investigating the adoption of four ecommerce applications currently available to Internet users: online shopping, online banking, online investing and electronic payment for an Internet service (i.e., access to exclusive sites) (Eastin 2002). He shows that attributes of IDT like perceived convenience and financial benefits, risk, previous use of the telephone for a similar purpose, self-efficacy and Internet use are significant variables of the adoption process. In their study Rangaswamy and Gupta (2000) analyse the adoption process of free digital products such as free software or e-commerce of non-digital products where the adoption decisions occur online and physical exchange takes place outside digital media.

Due to the proven applicability of IDT, the attributes influencing the e-commerce adoption of paid content presented in the scientific literature, and the analyses discussed above concerning electronic markets we will derive a model of adoption and diffusion of paid content.

\section{ADOPTION AND DIFFUSION OF PAID CONTENT}

\section{The Innovation Diffusion Theory}

The Innovation Diffusion Theory (IDT) allowed researchers to investigate how new innovations spread among groups of people. Rogers defines diffusion as 'the process by which an innovation is communicated through certain channels over time among the members of a social system. Diffusion is a special type of communication concerned with the spread of messages that are perceived as new ideas' (Rogers 2003: 35). Crucial for diffusion is the innovation-decision process which results in the adoption of an innovation. 'The innovation-decision process can lead to either adoption, a decision to make full use of an innovation as the best course of action available or rejection, a decision not to adopt an innovation' (Rogers 2003: 21). Users' approval of innovation and a classification of the users of an innovation is measured based on the variable 'relative time' at which an innovation is adopted. The rate of adoption is defined as 'the relative speed with which an innovation is adopted by members of a social system' (Rogers 2003: 23). The cumulative frequency distribution of the adoption of an innovation over time can be represented as an S-shaped curve. According to Rogers most of the variance in the rate of adoption of innovations is explained by five attributes: relative advantage; compatibility; complexity; trialability; and observability. Adoption is determined not only by these five attributes but also by variables such as: (i) the type of innovation-decision; (ii) the nature of communication channels (e.g., mass media or interpersonal); (iii) the nature of the Social System (e.g., its norms, degree of network interconnectedness etc.); or (iv) the extent of a change agent's promotion efforts (Rogers 2003: 221). Dearing et al. (1994) reported additional variables that have been used by researchers to define the adoption process: economic advantage; effectiveness; observability; trialability; complexity; compatibility; reliability; application; communality; and radicalness (Dearing et al. 1994, Eastin 2002). According to Eastin (2002) these variables are interdependent. While the diffusion model provides a framework with which to study a given innovation, each innovation differs and should be conceptualized based on its specific attributes (Eastin 2002).

\section{Attributes of paid content}

Several studies show that innovation and in particular technological innovation has a higher adoption rate if its general characteristics are compatible with known products and technologies (Dearing et al. 1994; Eastin 2002; LaRose and Atkin 1992; Perse and Courtright 1993). Rogers discusses this with the concept of 
compatibility. 'Compatibility is the degree to which an innovation is perceived as consistent with the existing values, past experiences, and needs of potential adopters' [Rogers 2003: 240). According to Rogers an innovation has a higher rate of adoption if it is compatible with the experiences of the users. This means that a new product is adopted more rapidly by users if it is already familiar from other situations.

LaRose and Atkin (1992) were, in the context of information technology, among the first to point out the relationship between users' adoption of technologies that provide information on demand and similar services they already use. They show that the use of videotext, ATMs and 800 numbers were all predictors of the adoption of local audiotext information services. Venkatesh et al.(2003) indirectly discuss the importance of user compatibility as an aspect of adoption with the concept 'effort expectancy'. 'Effort expectancy is defined as the degree of ease associated with the use of the system. Three constructs from the existing models capture the concept of effort expectancy: perceived ease of use (TAM/TAM2), complexity (MPCU), and ease of use (IDT)' (Venkatesh et al. 2003: 450). Venkatesh et al. demonstrate that the effect of effort expectancy on intention is also moderated by gender and age such that it is more significant for women and older workers, and those effects decrease with experience (Venkatesh et al. 2003). Using empirical data Eastin (2002) provides clear evidence that a relationship exists between compatible innovations such as home shopping and banking over the telephone and the adoption of their Internet-based e-commerce counterparts. Based on these research results the following hypothesis for the adoption of paid content will be derived:

Hypothesis 1: Paid content products with established, non-digital counterparts are adopted more rapidly and faster than those without.

Eastin (2002) discusses the importance of acquired skills and self-efficacy with respect to the diffusion of an innovation which predicts a faster adoption when a technology is easier to use. Eastin measures the level of skill in his study by the amount of time people spend on the Internet (i.e., Internet use will be based on the amount of time spent online). Based on the evidence provided so far, being in principle capable of using micropayment systems and paid content has a positive effect on the adoption of a specific paid content product (Krüger 2005). The basic assumption is that the more a user uses a particular service the higher her competence and skills. This view is supported by IS research on firm level (Zhu and Kraemer 2005). Experience and familiarity are state indicators for the level of skills and experience attributed to the use of a particular innovation. They increase asymptotically until they reach a level where they are perceived as common knowledge.
Compatibility is a concept associated with familiarity. It measures the degree to which new innovations are perceived to be compatible with existing values, needs, and past experiences (Moore and Benbasat 1991, Rogers 2003). The significance of skills, experience and familiarity for the adoption of paid content will be measured using the period of time for which a user has been purchasing content by means of the micropayment system and using the frequency of his purchases of digital products. We posit the following hypothesis for the analysis of the adoption of paid content.

Hypothesis 2: Experience and familiarity with paid content and micropayment will have a positive relationship with the rate of adoption of paid content products.

Another characteristic of innovations which, according to Rogers, is a predictor of adoption and diffusion, is the 'relative advantage'. 'The degree of relative advantage may be measured in economic terms, but social prestige factors, convenience, and satisfaction are also important factors ... The greater the perceived relative advantage of an innovation, the more rapid its rate of adoption will be' (Rogers 2003: 15). Eastin (2002) has reported that perceived benefits such as economic, time saved, and overall convenience were found to be strong predictors in the adoption of telephone and cable services (LLaRose and Atkin 1992; Eastin 2002). Eastin empirically showed that economic advantage and overall convenience are important components in e-commerce participation and thus should predict adoption. With respect to the adoption of paid content this relationship will be discussed using the following hypothesis:

Hypothesis 3: Economic advantage and perceived convenience of the paid content product will have a positive relationship to the rate of adoption of the paid content products.

A model demonstrating each adoption and diffusion attribute influencing the e-commerce adoption of paid content is illustrated in Figure 1.

\section{Empirical analysis}

Sample. The hypotheses for adoption and diffusion of paid content on electronic markets were tested on a set of data of a leading German micropayment provider, FIRSTGATE Internet AG. FIRSTGATE click\&buy ${ }^{(i m}$ is a micropayment system where users register only once in order to be able to buy paid content or services from all suppliers who settle their digital goods with this system. At the end of the month customers get only one bill from FIRSTGATE with a listing of all purchases. Between July 2000 and December 2003, 6.5 million purchase transactions from 1.6 million registered customers and 2,500 active sellers had been 


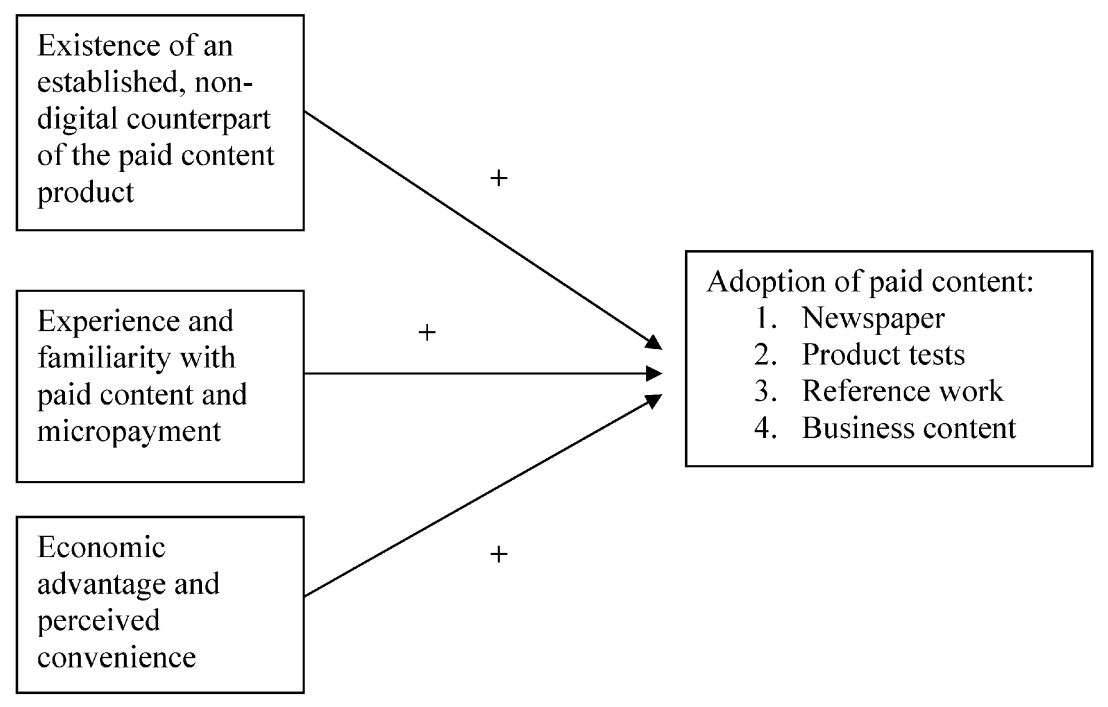

Figure 1. Attributes influencing the e-commerce adoption of paid content

handled. Each purchase transaction contains a customer and seller identification number (short 'ID'), date, time and the sum of revenues. The seller's dataset contains an ID, seller's name, the websites with URL and the different prices of offered goods. Because of the dominant market position of FIRSTGATE Internet AG, this dataset provides a large coverage and is a representative sample of the German paid content market. An example in the category 'product tests' is the online edition of Germany's leading product test provider 'Stiftung Warentest'; an example in the category 'general reference' is XIPOLIS, who provide certain articles from over 20 works of reference; examples in the category 'business' are the online products of the news channel N-TV.de, of Financial Times Germany, boerse-online.de or boerse.de.

The criterion of extraction of the sample was the following: each supplier had been offering his paid content products for more than 24 months, i.e. at least since January 2003 to December 2004. The sample includes 1,598,918 online transactions and 841,982 customers.

Design. To test the first hypothesis each supplier was classified by means of a variable indicating whether (s)he was only offering his/her product online as paid content or on another medium as well (e.g., as a book or on CD-ROM). It was crucial to the analysis that the product was already available before it was marketed as paid content, thus making it possible for customers to gain experience in the consumption of the product.

For the analysis of hypothesis 1 the proportion of adoptions during the first $50(100 / 200)$ days was calculated relative to the total number of adoptions over the first two years. The influence of a non-digital counterpart (dummy variable $=1$ ) on the proportion of adoptions during the first $50(100 / 200)$ days was tested by means of an analysis of variance (ANOVA).

For the analysis of the second hypothesis the number of days was calculated for each customer between his registration with the micropayment provider and his first adoption of a supplier's product. Another variable used for the analysis is the number of paid content transactions effected through the micropayment provider in the period between the registration and the first purchase of one of the products of the 24 product providers. Together with the period, the number of paid content transactions is an indicator for the experience and familiarity with paid content and micropayment.

Hypothesis 2 was considered based on the influence of the number of transactions (which a customer effected before the first adoption of a product) and the time period (between a customer's registration and the first adoption of a product) on the period between the launch of a product and the first adoption. The influence of familiarity, given by the period between registration and adoption as well as by the number of transactions prior to the first adoption, on the period between the launch of a product and adoption was tested by means of a multiple regression analysis.

The third hypothesis was tested using variables which act as indicators for 'perceived convenience'. As opposed to paid content from newspapers or providers of product tests who merely offer a digital equivalent of their products online, the general reference providers have the advantage of being up-to-date and of permitting comprehensive access to parallel articles of several editions or different works of reference. Whereas the complete print editions are very expensive and can become obsolete very quickly, the digital editions are always kept up-to-date, are always available given an Internet connection and the costs for single paid content 
articles are low in comparison to the print version. As availability, price and being up-to-date are indicators for 'economic advantage' and 'perceived convenience' - as has been shown by several studies (cf. Von Reibnitz et al.) - the paid content provider of reference works was analysed in regard to the 'economic advantage' and 'perceived convenience'.

Analysis. The analysis of the data was performed in several steps by calculating descriptive statistics as well as using quantitative methods. Multiple regression analysis and the analysis of variance (ANOVA) were used to test hypotheses $1-3$. The multiple regression analysis allows a detailed understanding of how the independent variables influence the predicted adoption. The analysis of variance is a method, which analyses the effect of one or several independent variables (e.g., the existence of an established, non-digital counterpart) in relation to one dependent variable (e.g., number of purchase transactions) (Backhaus et al. 2003).

Results. As regards hypothesis 1 the result of the empirical analysis of all adoptions within the first 50 (100/ 200) days after a product's launch was that for all product categories there is a strong correlation between the existence of a non-digital counterpart and the adoption of a product. The hypothesis is confirmed that the existence of a non-digital counterpart has a strong positive influence on the adoption of a product. Comparing the correlation coefficients in Table 1 it becomes apparent that the strength of the correlation between the existence of a non-digital counterpart and adoption decreases with the duration of the product's availability. This means that the influence of a nondigital counterpart only has an effect on consumers who adopt the product soon after its launch. Within the individual product categories large differences can be discerned. In the product categories 'product tests' and

Table 1. Coefficients of correlation between the existence of a non-digital counterpart and adoption within the first 50 (100/ 200) days after a product launch

\begin{tabular}{lccc} 
& $\begin{array}{c}\text { Adoption within } \\
\text { the first } 50 \\
\text { days }\end{array}$ & $\begin{array}{c}\text { Adoption within } \\
\text { the first } 100 \\
\text { days }\end{array}$ & $\begin{array}{c}\text { Adoption within } \\
\text { the first 200 } \\
\text { days }\end{array}$ \\
\hline Total & 0.6807 & 0.6595 & 0.5642 \\
Newspaper & 0.6391 & 0.8004 & 0.7573 \\
$\begin{array}{c}\text { Product } \\
\text { tests }\end{array}$ & 0.9975 & 0.5802 & 0.3574 \\
$\begin{array}{c}\text { Reference } \\
\text { work }\end{array}$ & 0.4762 & 0.4219 & 0.3955 \\
Business & 0.8119 & 0.7655 & 0.6304 \\
content & & & \\
\hline
\end{tabular}

Table 2. ANOVA: influence of a non-digital counterpart on adoption within the first 50 days after launch

\begin{tabular}{lrrc} 
& R-squared & F value & $\begin{array}{r}\text { Prob> F at a 99\% } \\
\text { confidence interval }\end{array}$ \\
\hline Total & 0.4633 & 18.99 & 0.0003 \\
Newspaper & 0.4085 & 2.76 & 0.1718 \\
Product tests & 0.9950 & 200.22 & 0.0449 \\
Reference work & 0.2268 & 1.47 & 0.2800 \\
Business & 0.6591 & 13.53 & 0.0079 \\
$\quad$ content & & & \\
\hline
\end{tabular}

'business content' the correlation with adoption is very pronounced within the first 50 days. In the category 'newspaper' the correlation between the existence of a non-digital counterpart and adoption is higher in the period 100 days after the launch than in the period 50 days after launch.

The statistical significance of the influence of the nondigital counterpart was tested using analysis of variance (ANOVA). As shown in Tables 2, 3 and 4 a highly significant influence of the existence of a non-digital counterpart on the adoption of a product can be identified. With a 99\% confidence interval a Prob $>F$

Table 3. ANOVA: influence of a non-digital counterpart on adoption within the first 100 days after launch

\begin{tabular}{llrc} 
& & & $\begin{array}{c}\text { Prob }>\text { F at a 99\% } \\
\text { confidence } \\
\text { interval }\end{array}$ \\
\hline Total & R-squared & F value & 0.0005 \\
Newspaper & 0.4349 & 16.93 & 0.0558 \\
Product tests & 0.6407 & 7.13 & 0.1601 \\
Reference work & 0.61354 & 11.16 & 0.3458 \\
Business & 0.1780 & 1.08 & 0.0162 \\
$\quad$ content & 0.5860 & 9.91 & \\
\hline
\end{tabular}

Table 4. ANOVA: influence of a non-digital counterpart on adoption within the first 200 days after launch

\begin{tabular}{lccc} 
& & & $\begin{array}{c}\text { Prob }>\text { F at a 99\% } \\
\text { confidence } \\
\text { interval }\end{array}$ \\
\hline Total & R-squared & F value & 0.0041 \\
Newspaper & 0.3183 & 10.27 & 0.0812 \\
Product tests & 0.5735 & 5.38 & 0.1973 \\
Reference work & 0.3278 & 5.15 & 0.3799 \\
Business & 0.1564 & 0.93 & 0.0687 \\
$\quad$ content & 0.3974 & 4.62 & \\
\hline
\end{tabular}


value of 0.0003 is found which is an indicator of very high significance.

The significance values of the analysis of variances (ANOVA) also clearly demonstrate that the influence of a non-digital counterpart on adoption is considerably stronger in the first 50 days than in the first 100 or 200 days. Examination of the $\mathrm{F}$ values reveals that the existence of a non-digital counterpart has a more persistent effect in the product category 'newspaper' than in the other content categories - the F value is twice as high in the analysis of the 100 day period as in that of the 50 day period after the launch of a product. If one includes all providers in the analysis a much larger influence of the non-digital counterpart $\left(\mathrm{R}^{2}=0.4633, \mathrm{~F}\right.$ value $=18.99$, Prob $>F$ at a $99 \%$ confidence inter$\mathrm{val}=0.0003)$ can be identified for the consumers who adopt the product within the first 50 days than those who adopt it within the first 100 days $\left(\mathrm{R}^{2}=0.4349, \mathrm{~F}\right.$ value $=16.93$, Prob $>F$ at a $99 \%$ confidence inter$\mathrm{val}=0.0005)$ or the first 200 days $\left(\mathrm{R}^{2}=0.3183, \mathrm{~F}\right.$ value $=10.27$, Prob $>F$ at a $99 \%$ confidence inter$\mathrm{val}=0.004 \mathrm{l})$ after the launch of a product.

The empirical analysis of the data in view of the relationships posited by hypothesis 2 shows that a strong negative correlation exists between the attribute of experience and familiarity with paid content - measured using the duration of the period between registration and the first adoption of a provider's product resp. using the number of a user's transactions in the same period and the period of time between the launch of a product and its adoption (cf. Table 5). The correlation coefficient's negative sign indicates that the longer a consumer has been registered or the more digital products a consumer has already purchased, the faster he adopts a new paid content product after its launch.

The influence of the number of a user's transactions in the period between registration and the first adoption of a product (independent variable) or the duration of the period between the registration and the first adoption of a product (independent variable) on the period between

Table 5. Coefficients of correlation between the period between registration and first adoption of a product and the number of a user's transactions in the period between registration and the first adoption of a product (independent variables) and adoption within the first $50(100 / 200)$ days (dependent variable)

Time period between product launch and adoption

\begin{tabular}{ll}
\hline Time period between registration & -0.3145 \\
and first adoption of a product & \\
& \\
Number of a user's transactions & -0.7115 \\
between the registration and & \\
the first adoption of a product &
\end{tabular}

Table 6. Coefficients of correlation between the attribute 'perceived convenience' of a product and adoption within the first $50(100 / 200)$ days after launch

\begin{tabular}{lccc} 
& & Adoption within & Adoption within \\
& $\begin{array}{c}\text { Adoption within } \\
\text { the first 50 days }\end{array}$ & $\begin{array}{c}\text { the first } \\
100 \text { days }\end{array}$ & $\begin{array}{c}\text { the first } \\
200 \text { days }\end{array}$ \\
\hline Total & 0.4304 & 0.3764 & 0.3406 \\
Reference work & 0.5212 & 0.5798 & 0.6050 \\
\hline
\end{tabular}

the launch of a product and adoption (dependent variable) was further tested with the help of a multiple regression. The results of the regression analysis show that when considering all adoptions within the first 100 days after the launch of a product there is a significant linear relationship $\left(\mathrm{R}^{2}=0.5453, \mathrm{t}\right.$ value $=1.31$, Prob $>t$ at a $99 \%$ confidence interval $=0.204$ ) between the number of a user's transactions in the period between registration and the first adoption of a product (independent variable), the duration of the period between registration and the first adoption of the product (independent variable) and the period between the launch of a product and adoption (dependent variable).

For the analysis of hypothesis 3 concerning the influence of 'economic advantage' and 'perceived convenience' on adoption of a product, the correlation coefficient was calculated between the attribute 'economic advantage' resp. 'perceived convenience' of a paid content product and the number of adoptions effected within the first $50(199 / 200)$ days after the launch of the product. As can be seen in Table 6 there is a strong correlation between the attribute 'perceived convenience' and the adoption of a product when all products are considered and in particular for the product category 'reference work'. The power of the correlation coefficient decreases, however, as the period of time considered in the analysis increases. Conversely, in the product category 'reference work' the correlation coefficient increases with the period of time considered for the analysis.

The significance of the influence of 'economic advantage' and 'perceived convenience' on the adoption of a product was tested by means of analysis of variances (ANOVA). As shown in Table 7 a highly significant influence of the 'economic advantage' and 'perceived convenience' on the adoption of a product can be identified in the product category 'reference work' (50 days: $\mathrm{R}^{2}=0.2717,100$ days: $\mathrm{R}^{2}=0.3362,200$ days: $\mathrm{R}^{2}=0.3660$ ). With a $99 \%$ confidence interval a Prob $>\mathrm{F}$ value of 0.0003 is found which is an indicator for very high significance.

These statistics fully support the assumptions that the 'existence of an established, non-digital counterpart' of the paid content product, 'experience' and 'familiarity' 
Table 7. Results of ANOVA: influence of 'perceived convenience' on adoption within the first $50(100 / 200)$ days after launch of a product

\begin{tabular}{|c|c|c|c|}
\hline & $R$-squared & F value & $\begin{array}{c}\text { Prob }>F \text { at a } \\
99 \% \text { confidence } \\
\text { interval }\end{array}$ \\
\hline \multicolumn{4}{|c|}{ Adoptions within the first 50 days } \\
\hline Total & 0.1852 & 5.00 & 0.0358 \\
\hline Reference work & 0.2717 & 1.49 & 0.2890 \\
\hline \multicolumn{4}{|c|}{ Adoptions within the first 100 days } \\
\hline Total & 0.1417 & 3.63 & 0.0698 \\
\hline Reference work & 0.3362 & 2.03 & 0.2277 \\
\hline \multicolumn{4}{|c|}{ Adoptions within the first 200 days } \\
\hline Total & 0.1160 & 2.89 & 0.1034 \\
\hline Reference work & 0.3660 & 2.31 & 0.2033 \\
\hline
\end{tabular}

with paid content and micropayment and 'economic advantage' and 'perceived convenience' are attributes that influence the adoption of a paid content product. In the following section the empirical results will be discussed in the context of the hypotheses and the theoretical approaches.

\section{DISCUSSION AND IMPLICATIONS}

This study has focused on the adoption and diffusion of paid content mediated by German Electronic Markets based on a large set of transactions. All attributes that were analysed in detail showed significant influence on diffusion and adoption of digital paid content.

Linear and multiple regression analysis on the basis of large transaction sets of paid content customers showed strong characteristic adoption effects. It was shown that adoption of paid content is influenced by customer experience with paid content in digital and non-digital scenarios and micropayments, while on the content provider side diffusion was influenced by the product portfolio of digital and non-digital paid content. This study gives initial indications on the interplay of customer knowledge and provider decisions on product designs within the domain of digital paid content products.

Previous experience of non-digital content products generally results in a strong positive influence on the time of adoption of digital paid content offered by the same provider during the first phase of the digital offering. It was shown for paid content that this has a strong influence on early adopters during the first 50 days after product launch whereas this influence degrades over time. This effect resembles Rogers' compatibility attribute (Rogers 2003) in the sense that users gained knowledge and experience with non-digital counterparts that can be used as a frame of reference for adopting innovations of content products in digital environments.

This view is supported by the second result that consumers of paid content with longer experience with paid content and micropayment services adopt new paid content products earlier than those with less experience. This result is consistent with LaRose' and Atkin's (1992) research on the positive influence of experience with videotext, ATMs and 800 numbers on the adoption of local audiotext information services and Eastin's (2002) results on the adoption of closely related online services. For a content provider this means that at an early stage more experienced consumers will test paid content products while the less experienced will arrive at later stages.

These two findings give an indication that the adoption of paid content follows a two step process. First consumers try to reuse and transfer knowledge and experiences with non-digital paid content to the digital world. With increasing knowledge and experience with digital paid content products and micropayment systems consumers receive confidence which results in faster adoption of new types of paid content products.

Paid content supports different consumer needs, such as entertainment and leisure, obtainment of background information and decision making. Content that generally supports knowledge workers is comprised of the latter two categories whereby background information has indirect effects and content for decision making which might eventually result in direct effects on knowledge work (Blomberg 1986) and firm's performance (Brynjolfsson et al. 1998). Reference-work content can be classified as a content type that supports decision making as a knowledge tool that substitutes the use of expensive encyclopaedic books. Because reference-work content is provided on a pay-per-use basis this contrasts with the traditional buying of an integrated encyclopaedia. Users must initially adopt this innovation by valuation of cost-benefit potentials before they can integrate this innovation into their working behaviour which results in delayed adoption of reference-work products. But in contrast to content that translates non-digital usage patterns into the digital domain, initial adoption of reference work steadily increases over time which indicates word-of-mouth and other network effects in and between communities. In this way, knowledge of and experiences with the innovation of a particular paid content product might be communicated within a particular community, reducing uncertainty for later adopters regarding risk of failure, usage patterns and general trust with the innovation before its initial adoption.

This study provides some initial indications for the influence of translating expertise with buying paid content in non-digital environments to digital environments and how growing experience with digital paid content influences future buying behaviour of paid 
content. In addition to translation effects, it was shown how behaviour diffuses through communities over time based on an increase of the economic advantage and convenience for knowledge work. In summary, the buying behaviour of consumers of paid content initially rests on knowledge gained in traditional, non-digital worlds and is also influenced by expertise accumulated in digital worlds as well as by diffusion effects within communities that use digital paid content.

\section{Future work}

Paid content is still an innovation in its early stage (Picot et al. 2001, Stahl 2005, Zerdick et al. 2001). In fact, paid content was assumed to be almost impossible in the early days of e-commerce, when content generally had to be for free and subsidized by online advertisements (Dewan et al. 2003). But high search costs and heterogeneous quality levels of free content nurtured the market for high-quality paid content markets for particular needs and on particular topics (Davenport and Beck 2001). The three categories of paid content used in this study have been entertainment, background information and decision-making content. How these content categories diffuse into different communities and become adopted by individuals is a challenging research direction. Communities of knowledge workers will probably adopt content categories that are: consistent with their work domain; fit to their current need (Todd and Benbasat 1992); individual content rating (Poston and Speier 2005); and are provided by services that support their knowledge work (Davenport et al. 2003); which might be viewed by a concept such as relative advantage (Rogers 2003); perceived usefulness (Davis 1989) and performance expectancy (Venkatesh et al. 2003).

This study focused on general influences of experience with non-digital counterparts, experience with paid content and micropayments. The analyses of the first hypothesis indicate that content types do not behave homogeneously (see Table 2). For instance, it seems that experience with non-digital counterparts for product tests is more important for consumers that adopt an offering at an very early stage while reference work is more or less independent of experience within nondigital domains. This differential might be based on the difference of underlying payment methods, changed usage patterns or individual factors such as perceived convenience.

Limitations of the empirical analysis and the findings are that they are based on a single case study from a German data set, which makes it difficult to generalize the results for other paid content markets. The relationship between non-digital and digital paid content products is embedded into the overall product and pricing strategy of a firm (Skiera and Spann 2002; Stahl
2005). Any attribute associated with a firm is superimposed on each product. Therefore, it can be assumed that a firm's brand positively or also negatively moderates the flow of experience and knowledge from non-digital to digital paid content products (e.g., Richardson and Dick 1994; Wen-yeh et al. 2004) which is a possible explanation that product tests show strong affection to existence of non-digital counterparts. This leads to the question whether similar content products with non-digital counterparts provided by firms from different branding classes show different adoption and diffusion effects, i.e., 'How important is branding for paid content'?

Following the economic principle that buying a product satisfies a need, further research on paid content that support knowledge work would give important insights about how external high-quality content diffuses through communities and how individual behaviour of knowledge workers changes over time, which would extend research on adoption and diffusion of information technologies (e.g., Markus 1992). Consumers adopt innovations and adapt their behaviour depending on expected performance, social influence and facilitating conditions (Venkatesh et al. 2003). Based on the UTAUT model, the expected change of knowledge work could be investigated.

\section{References}

Ajzen, I. (1991) 'The Theory of Planned Behavior', Organizational Behavior and Human Decision Processes 50: 179-211.

Ajzen, I. and Fishbein, M. (1980) Understanding Attidues and Prediciting Social Behaviour, Englewood Cliffs, NJ:

Prentice Hall.

Backhaus, K., Erichson, B., Plinke, W. and Weiber, R. (2003) Multivariate Analysemethoden. Eine anwendungsorientierte Einfübrung, 10th edn, Berlin: Springer.

Bandura, A. (1977) 'Toward a Unifying Theory of Behavioral Change', Psychological Review 84: 191-215.

Bandura, A. (1986) Social Foundations of Thought and Action, Englewood Cliffs, NJ: Prentice Hall.

Bass, F. M. (1969) 'A New Product Growth for Model Consumer Durables', Management Science 15: 215-27.

Blomberg, J. (1986) 'The Variable Impact of Computer Technologies on the Organization of Work Activities', Proceedings of the Conference on Computer Supported Cooperative Work, pp. 35-42.

Brandtweiner, R. (2000) Differenzierung und elektronischer Vertrieb digitaler Informationsgüter, Düsseldorf: Symposium Publishing.

Brynjolfsson, E., Hitt, L. and Yang, S. (1998) 'Intangible Assets: How the Interaction of Computers and Organizational Structure Affects Stock Market Valuations', Proceedings of the International Conference on Information Systems, pp. 8-29. 
Bughin, J. (2003) 'The Diffusion of Internet Banking in Western Europe', EM - Electronic Markets 13: 251-8.

Choi, S.-Y., Stahl, D. O. and Whinston, A. B. (1997) The Economics of Electronic Commerce, Indianapolis: Macmillan Technical Publishing.

Clarke, R. (2005) 'Electronic Commerce Definitions', online at: http://www.anu.edu.au/people/Roger.Clarke/EC/ ECDefns.html, accessed 30 April 2005.

Compeau, D. R. and Higgins, C. A. (1995) 'Computer Selfefficacy: Development of a Measure and Initial Test', MIS Quarterly 19: 189-211.

Crimmins, J. (1992) 'Better Measurement and Management of Brand Value', Journal of Advertising Research 32: 11-19.

Davis, F. D. (1989) 'Perceived Usefulness, Perceived Ease of Use, and User Acceptance of Information Technology', MIS Onarterly 13: 319-39.

Davis, F. D., Bagozzi, R. P. and Warshaw, P. R. (1989) 'User Acceptance of Computer Technology: A Comparison of Two Theoretical Models', Management Science 35: 982-1002.

Davis, F. D., Bagozzi, R. P. and Warshaw, P. R. (1992) 'Extrinsic and Intrinsic Motivation to use Computers in the Workplace', Journal of Applied Social Psychology 22: 1111-32.

Davenport, T. and Beck, J. (2001) The Attention Economy: Understanding the New Currency of Business, Boston: Harvard Business School Publishing.

Davenport, T., Thomas, K. and Desouza, K. (2003) 'Reusing Intellectual Assets', Industrial Management 45: 12-18.

Dearing, J., Meyer, G. and Kazmierczak, J. (1994) 'Portraying the New: Communication Between University Innovators and Potential Users', Science Communication 16: 11-42.

Dewan, R. M., Freiner, M. L. and Zhang, J. (2003) 'Management and Valuation of Advertisement-supported Web Sites', Journal of Management Information Systems 19: 87-98.

Dutton, W. H., Rogers, E. M. and Jun, S.-H. (1987) 'Diffusion and Social Impacts of Personal Computers', Communication Research 14(2) (April): 219-50.

Eastin, M. J. (2002) 'Diffusion of E-commerce: An Analysis of the Adoption of Four E-commerce Activities', Telematics and Informatics 19: 251-67.

Fishbein, M. and Ajzen, I. (1975) Belief, Atitude, Intention and Behaviour: An Introduction to Theory and Research, Reading, MA: Addison-Wesley.

Goodhue, D. L. (1995) 'Understanding User Evaluations of Information Systems', Management Science 41: 1827-44.

Goodhue, D. L. and Thompson, R. L. (1995) 'TaskTechnology Fit and Individual Performance', MIS Quarterly 9: 213-36.

Haines, G. (1964) 'A Theory of Market Behavior After Innovation', Management Science 4: 634-58.

Harrison, D. A., Mykytyn, P. P. and Riemenschneider, C. K. (1997) 'Executive Decisions About Adoption of Information Technology in Small Business: Theory and Empirical Tests', Information Systems Research 8: 171-95.
Hoffman, D. L., Novak, T. P. and Chatterjee, P. (1995) 'Commercial Scenarios for the Web: Opportunities and Challenges', Journal of Computer Mediated Communication 1(3), online at: http://jcmc.indiana.edu/ voll/issue3/hoffman.html.

Hu, P. J., Chau, P. Y. K., Sheng, O. R. L. and Tam, K. Y. (1999) 'Examining the Technology Acceptance Model Using Physician Acceptance of Telemedicine Technology', Journal of Management Information Systems 16: 91-112.

Krishnan, T., Bass, F. and Jain, D. (1999) 'Optimal Pricing Strategy for New Products', Management Science 45: 1650-63.

Krüger, M. (2005) 'Internet Zahlungssysteme aus der Sicht der Verbraucher Ergebnisse der Online-Umfrage IZV7', online at: http://www.iww.uni-karlsruhe.de/izv/pdf/ izv7_auswertung.pdf, accessed 10 September 2005.

Kshetri, N. and Dholakia, N. (2002) 'Determinants of the Global Diffusion of B2B E-Commerce', EM-Electronic Markets 12: 120-9.

LaRose, R. and Atkin, D. (1992) 'Audiotext and the Reinvention of the Telephone as a Mass Medium', Journalism Quarterly 69: 413-21.

Leonard-Barton, D. and Deschamps, I. (1988) 'Managerial Influence in the Implementation of New Technology', Management Science 34: 1252-65.

Liang, T.-P. and Huang, J.-S. (1998) 'An Empirical Study on Consumer Acceptance of Products in Electronic Markets: A Transaction Cost Model', Decision Support Systems 24(1): 29-43.

Mahajan, V. and Muller, E. (1979) 'Innovation Diffusion and New Product Growth Models in Marketing', Journal of Marketing 43: 55-68.

Mahajan, V., Muller, E. and Bass, F. M. (1990) 'New Product Diffusion Models in Marketing: A Review and Directions for Research', Journal of Marketing 54: 1-26.

Mahajan, V., Muller, E. and Wind, Y. (2000) New-Product Diffusion Models: From Theory To Practice, Boston: Kluwer Academic Publishers.

Malone, T., Yates, B. and Benjamin, R. (1987) 'Electronic Markets and Electronic Hierarchies: Effects of Information Technology on Market Structure and Corporate Strategies', Communications of the ACM 30: 484-97.

Markus, L. (1992) 'Electronic Mail as the Medium of Managerial Choice', Organization Science 5: 502-27.

Mathieson, K. (1991) 'Predicting User Intentions: Comparing the Technology Acceptance Model with the Theory of Planned Behavior', Information Systems Research 2: 173-91.

Moore, G. C. and Benbasat, I. (1991) 'Development of an Instrument to Measure the Perceptions of Adopting an Information Technology Innovation', Information Systems Research 2: 173-91.

Perse, E. M. and Courtright, J. A. (1993) 'Normative Images of Communication Media: Mass and Interpersonal Channels in the New Media Environment', Human Communication Research 19: 485-503. 
Picot, A., Reichwald, R. and Wigand, R. (2001) Die grenzenlose Unternehmenung - Die Überwindung von Standortgrenzen, Wiesbaden: Gabler Verlag.

Poston, R. S. and Speier, C. (2005) 'Effective Use of Knowledge Management Systems: A Process Model of Content Ratings and Credibility Indicators', MIS Quarterly 29: 221-44.

Rangaswamy, A. and Gupta, S. (2000) Innovation Adoption and Diffusion in the Digital Environment: Some Research Opportunities, Boston: Kluwer Academic Publishers.

Richardson, P. and Dick, A. (1994) 'Extrinsic and Intrinsic Cue Effects on Perceptions of Store Brand Quality', Journal of Marketing Research 36: 258-68.

Robinson, B. and Lakhani, C. (1975) 'Dynamic Pricing Models for New Product Planning', Management Science 21: 1113-22.

Rogers, E. M. (2003) Diffusion of Innovations, 5th edn, New York: Free Press.

Shapiro, C. and Varian, H. R. (1999) Information Rules - A Strategic Guide to the Network Economy, Boston: Harvard Business School Press.

Shih, C. and Venkatesh, A. (2004) 'Beyond Adoption: Development and Application of a Use-Diffusion Model', Journal of Marketing 68: 59-72.

Skiera, B. and Spann, M. (2002) 'Preisdifferenzierung im Internet', in M. Schögel, T. Tomczak and C. Belz (eds) Roadmap to E-Business - Wie Unternehmen das Internet erfolgreich nutzen, St. Gallen: Thexis, pp. 270-84.

Stahl, F. (2005) Strategien zur Preisgestaltung beim Elektronischen Handel Digitaler Inbalte, Wiesbaden: Deutscher Universitätsverlag (DUV).

Taylor, S. and Todd, P. (1995) 'Assessing IT Usage: The Role of Prior Experience’, MIS Quarterly 19: 561-70.
Thompson, R. L., Higgins, C. A. and Howell, J. M. (1991) 'Personal Computing: Toward a Conceptual Model of Utilization', MIS Quarterly 15: 125-43.

Todd, P. and Benbasat, I. (1992) 'The Use of Knowledge in Decision Making: An Experimental Investigation of the Impact of Computer-Based Decision Aids', MIS Quarterly 16: 373-93.

Varian, H. R. (1998) 'Market for Information Goods', Proc. of the Monetary Policy in a World of Knowledge-Based Growth, Quality Change and Uncertain Measurement.

Venkatesh, V., Morris, M. G., Davis, G. B. and Davis, F. D. (2003) 'User Acceptance of Information Technology: Toward a Unified View', MIS Quarterly 27: 425-78.

Von Reibnitz, A., Rautenberg, A. and Schwaiger, M. (2003) Pricing von Paid Content und Paid Services, Berlin: VDZ Verband Deutscher Zeitschriftenverleger.

Ward, P. and Davies, B. J. (1999) 'The Diffusion of Interactive Technology at the Customer Interface', International Journal of Technology Management 17(1/2): 84-108.

Wen-yeh, H., Schank, H. and Dubinsky, A. (2004) 'Effect of Brand Name on Consumers' Risk Perceptions of Online Shopping', Journal of Consumer Behaviour 4: 40-50.

Zerdick, A., Picot, A., Schrape, K., Artope, A., Goldhammer, K., Heger, D. K., Lange, U. T., Vierkant, E., Lopez-Escobar, E. and Silverstone, R. (2001) Die InternetÖkonomie. Strategien für die digitale Wirtschaft (European Communication Council Report), Berlin: Springer.

Zhu, K. and Kraemer, K. (2005) 'Post-Adoption Variations in Usage and Value of E-Business by Organizations: CrossCountry Evidence from the Retail Industry', Information Systems Research 16: 61-84. 